\title{
Ventricular Tachycardia Caused by Intramyometrial Infiltration of Vasopressin during Laparoscopic Myomectomy: An Anesthesiologist's Nightmare
}

\author{
Rajashree D Godbole
}

\begin{abstract}
All endoscopic procedures demand minimal blood loss during surgery to achieve good visibility which facilitates the speed of surgery. Vasopressin is often used for local infiltration during uterine myomectomy. It has good clinical effects but its systemic absorption may pose significant challenges for the anesthesiologist. It may sometimes lead to lethal complications. The loss of peripheral pulse along with bradycardia, nonmeasurable blood pressure, and cardiac complications have been reported after intramyometrial injection of vasopressin. Here, we describe a patient with multiple uterine fibroids who developed ventricular tachycardia within 2-3 minutes after intramyometrial infiltration of vasopressin diluted in normal saline. The total dose of vasopressin being 5.36 units ( 0.067 units $/ \mathrm{mL}$ ) with severe peripheral arterial vasospasm, increased blood pressure, and ventricular tachycardia followed by pulmonary edema. The patient was successfully resuscitated.

Keywords: Intramyometrial injection, Laparoscopic myomectomy, Vasopressin, Ventricular tachycardia.

The Journal of Medical Sciences (2019): 10.5005/jp-journals-10045-00118
\end{abstract}

\section{INTRODUCTION}

During laparoscopic myomectomy, intraoperative bleeding obstructs the vision so vasopressin infiltration is routinely used to reduce the blood loss and operative time, have clear vision, and to avoid blood transfusion and its complications. However, the use of vasopressin is not free of side effects and may sometime cause lethal complications like bradycardia, arrhythmias, pulmonary edema, and cardiac arrest. Most of the complications are supposed to be due to inadvertent intravascular injection of vasopressin solution. We report a case of ventricular tachycardia where cardioversion was required for resuscitation and the patient had pulmonary edema for which ventilation was required for 2 hours.

\section{Case Description}

A 36-year-female patient of primary infertility weighing $68 \mathrm{~kg}$ with multiple uterine fibroids was posted for laparoscopic myomectomy. Physical examination was unremarkable with normal hematological, biochemical investigation, and electrocardiogram. She had past history of open uterine myomectomy in 2005, cholecystectomy in 2007, and diagnostic laparoscopy in 2014. All procedures were uneventful. After arrival in the operation theater, the patient was monitored by three lead continuous ECG, pulse oximetry, and noninvasive blood pressure monitor. Her baseline vital parameters were the following: pulse $78 /$ minute, regular, blood pressure 130/82 $\mathrm{mm} \mathrm{Hg}$, oxygen saturation 99\%, and sinus rhythm on ECG. Intravenous line was secured on the right hand with 20 no. intracath and Ringer lactate started. The patient was given general anesthesia. Inj. fentanyl $100 \mu \mathrm{g}$ and midazolam $1 \mathrm{mg}$ IV given. Induction done with inj. propofol $100 \mathrm{mg}$ and vecuronium $6 \mathrm{mg}$ no. 7.5 cuffed endotracheal tube (ETT) put and the patient was ventilated in a closed circuit with intermittent positive pressure ventilation (IPPR) maintained with oxygen, nitrous oxide, and sevoflurane. End tidal carbon dioxide $\left(\mathrm{ETCO}_{2}\right)$ was monitored. Modified lithotomy position was given. After insertion of laparoscopy ports, there was a $8 \times 10 \times 4 \mathrm{~cm}$
Department of Anaesthesiology, Emerald Endoscopy Center, Pune, Maharashtra, India

Corresponding Author: Rajashree D Godbole, Department of Anaesthesiology, Emerald Endoscopy Center, Pune, Maharashtra, India, Phone: +91 9822049748, e-mail: rajashree.godbole@gmail.com

How to cite this article: Godbole RD. Ventricular Tachycardia Caused by Intramyometrial Infiltration of Vasopressin during Laparoscopic Myomectomy: An Anesthesiologist's Nightmare. J Med Sci 2019;5(2):57-58.

Source of support: Nil

Conflict of interest: None

fibroid on the anterior uterine wall and $8 \times 8 \times 6 \mathrm{~cm}$ fibroid in the right broad ligament. Twenty units of Vasopressin was diluted in $300 \mathrm{cc}$ NS $(0.067$ units $/ \mathrm{mL})$. About $80 \mathrm{cc}$ of this diluted vasopressin was infiltrated around the fibroid on the anterior uterine wall. The patient was stable hemodynamically. After 2-3 minutes of infiltration, the pulse volume was little low and the monitor started showing ventricular tachycardia. The surgeon was requested to stop the surgery. The patient was ventilated with $100 \%$ oxygen and $200 \mathrm{cc}$ Ringer lactate was given fast. Inj. xylocard $60 \mathrm{mg}$ bolus given. There was no change. Inj. amiodaron $150 \mathrm{mg}$ diluted in NS was given over 5 minutes and $150 \mathrm{mg}$ diluted in $50 \mathrm{cc}$ NS, infusion started with $3 \mathrm{cc} /$ hour. There was no change.

Cardioversion with $100 \mathrm{~J}$ was given-no change

2nd cardioversion with $200 \mathrm{~J}$ was given-no change

Third cardioversion with $200 \mathrm{~J}$ was given. Ventricular tachycardia reverted. The patient had normal regular cardiac rhythm. Her blood pressure was $70 / 50 \mathrm{~mm} \mathrm{Hg}$. NS $200 \mathrm{cc}$ was given fast. Her oxygen saturation was low- $80 \%$ with $100 \%$ oxygen IPPR. Patient had crepitations in the chest bilaterally. Inj. Lasix $40 \mathrm{mg}$ was given and $40 \mathrm{mg}$ was repeated after 20 minutes. The blood pressure was normal and the patient was stable hemodynamically with pulmonary edema. It was confirmed with chest X-ray (CXR). 
So she was ventilated with $100 \%$ oxygen and positive end expiratory pressure (PEEP) $4 \mathrm{~cm}$. After an hour, the chest was clear. The patient was fully awake, obeying commands, and maintaining oxygen saturation $98 \%$ without oxygen. So she was extubated and shifted to ICU for observation for the next 24 hours.

\section{Discussion}

Knowing lethal complication of vasopressin infiltration, it is still routinely used during gynecological surgeries like myomectomies and cervical conization.

Two cases of bradycardia followed by cardiac arrest and pulmonary edema after $6-10 \mathrm{~mL}$ of diluted vasopressin ( 2 units $/ \mathrm{mL}$ ) during open myomectomy are reported. ${ }^{1}$

Severe bradycardia and vasospasm followed by intramyometrial injection of vasopressin 20 units in $10 \mathrm{~mL}$ NS are reported during open myomectomy. ${ }^{2}$

Alexander and Brown recommended the concentration of dilute vasopressin to be less than $0.05-0.3$ units $/ \mathrm{mL}$ to avoid lethal complications. $^{3}$

Eight units of vasopressin in $40 \mathrm{~mL}$ NS were injected during open myomectomy. The patient had severe bradycardia, hypotension, pulmonary edema, cardiac failure, and death. ${ }^{4}$

Bradycardia and atrioventricular block with bigeminni was reported after injection of 3 units diluted vasopressin in the fibroid. ${ }^{5}$

A cumulative total dose of 4-6 units of vasopressin in a dilute solution to be a reasonable upper limit. ${ }^{6}$

Pisat visual vasopressin injection needle tip (Pisat's VVIN) has a disposable plastic transparent hub and a terminal metallic tip. The plastic transparent hub is $1 \mathrm{~cm}$ long and has a diameter of $2 \mathrm{~mm}$. With a standard laparoscopic metallic needle, $0.8 \mathrm{~mL}$ of solution is required to demonstrate a positive aspiration test. For Pisat's VVIN (Figs 1 and 2), the minimum aspiration quantity is reduced to $0.3 \mathrm{~mL}$. The surgeon can immediately see blood, withdraw the needle, and reposition it. This increases patient's safety. ${ }^{7}$

Uterine fibroids are rich in blood supply and the possibility of large dose of vasopressin getting absorbed into the blood vessels cannot be excluded. Coronary vasoconstriction, increased vagal tone, and sympathetic tone cause bradycardia, arrhythmias, decreased cardiac output, and, in severe cases, myocardial ischemic and death.

Although low doses of vasopressin have been used safely, hemodynamic complications have been reported with doses exceeding 5 units.

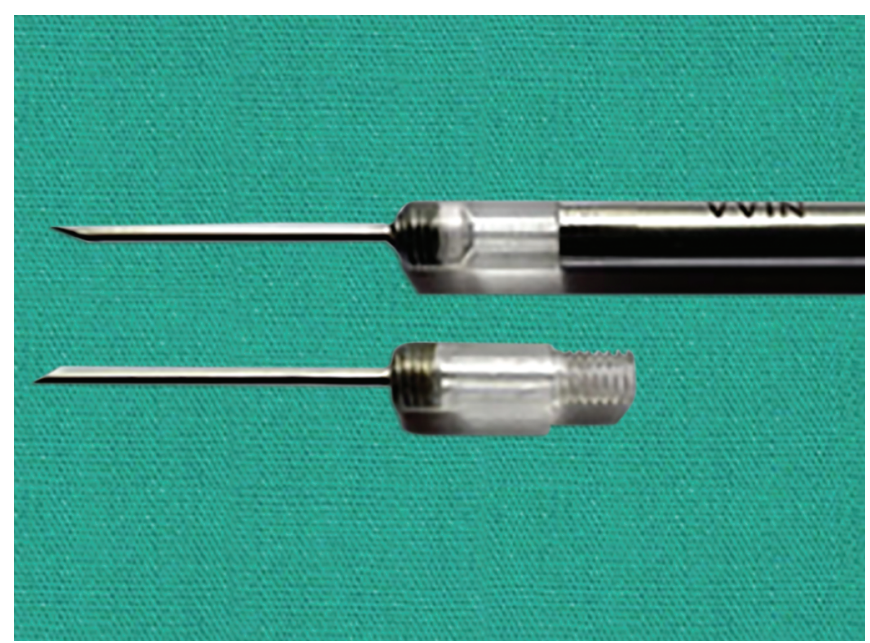

Fig. 1: Disposable transparent tip of VVIN

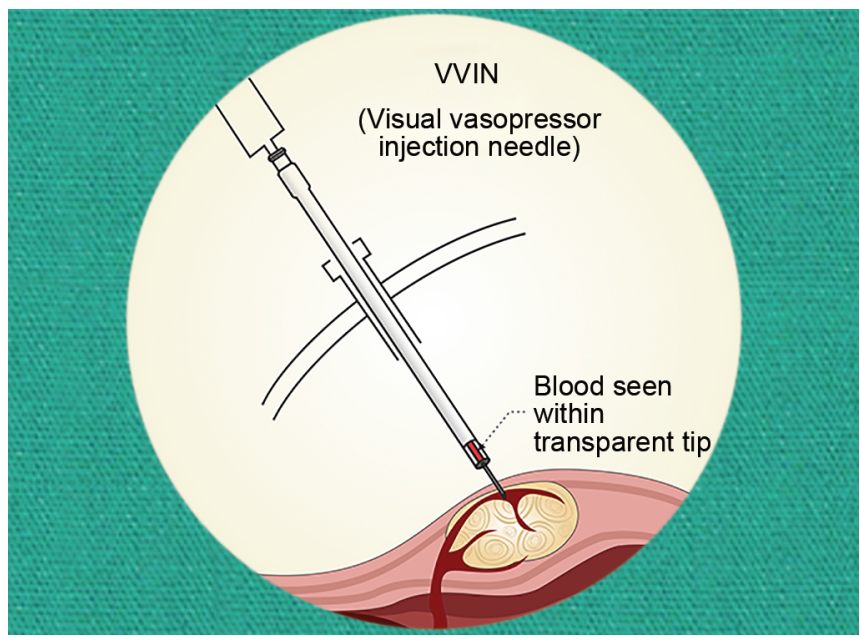

Fig. 2: Blood seen in the transparent tip of VVIN

In our patient, the dose of vasopressin was 5.36 units. But the volume of diluted vasopressin in NS was $80 \mathrm{cc}$. This increased total volume of diluted vasopressin increased pressure in the walls of the uterus facilitating the absorption of vasopressin into the highly vascular fibroid and in the uterine vessels.

\section{Conclusion}

To avoid lethal complications of vasopressin infiltration during open/laparoscopic myomectomy,

- The dilution of vasopressin should be $0.05-0.1$ units $/ \mathrm{mL}$ of NS and the total administered volume of diluted vasopressin with NS should be as small as possible.

- The total cumulative dose of vasopressin should not exceed 4-6 units.

- During laparoscopic procedure, the increased intra-abdominal pressure should always be kept in mind.

- The use of Pisat's VVIN can increase patient's safety.

- Careful hemodynamic monitoring is very essential.

- Close communication between the anesthesiologist and the gynecologist is very important to identify and treat these complications of vasopressin infiltration.

\section{References}

1. Hung $M H$, Wang $Y M$, et al. Intramyometrial injection of vasopressin causes bradycardia and cardiac arrest-report of 2 cases. Acta Anaesthesiol Taiwan 2006;44:243-247.

2. Butala BP, Shah VR, et al. Bradycardia and severe vasospasm caused by intramyometrial injection of vasopressin during myomectomy. Saudi J of Anaesth 2014;8(3):396-398.

3. Alexander GD. Morris Brown A safe dose of Vasopressin for paracervical infiltration. Anesth Analg 1995 Aug;81(2):428. DOI: 10.1213/00000539-199508000-00053.

4. Kabade SD, Sachidananda R, et al. Intramyometrial vasopressin: A fear for anesthetist? Saudi J Anaesth 2017 Oct-Dec;11(4):494-495. DOI: 10.4103/sja.SJA_102_17.

5. Deschamps A, Krishnamurthy S. Absence of pulse and blood pressure following vasopressin injection for myomectomy. Can J of Anaesthesia 2005;52:552-553. DOI: 10.1007/BF03016547.

6. Frishman G. Vasopressin: if some is good, is more better? Obstet Gynecol 2009(Pt 2):476-477. DOI: 10.1097/AOG.0b013e31819698bb.

7. Pisat SV. Pisat's visual vasopressin injection needle: a new device for increasing patient safety in laparoscopic myomectomy. J Obstet Gynaecol India 2017;67(6):451-453. DOI: 10.1007/s13224-0171048-6 